\title{
Left ventricular rupture after mitral valve replacement
}

\section{Tirone E. David, MD}

Ventricular rupture after mitral valve replacement (MVR) is a rare and often a fatal complication of this operation. This problem was first presented at the 39th Annual Meeting of the American College Chest Physicians in Toronto, on October 22, 1973, by Dr Robert L. Treasure and colleagues. ${ }^{1}$ Those investigators collected 7 cases from 3 hospitals and, based on the site of the ventricular tear, they classified the ventricular ruptures in type 1 (atrioventricular groove) and type 2 (midventricular wall). All patients underwent ventricular tear repair with large sutures buttressed on Teflon felt on the epicardial surface: 2 patients survived, and 5 died. A few years later, Zacharias and colleagues at the Cleveland Clinic reported 6 patients who developed ventricular rupture and died from a series of 1154 patients who had undergone MVR during their study period. ${ }^{2}$ The locations of the ventricular tears in these 6 patients were as described by Treasures as in either the atrioventricular groove or the midventricular wall. The authors believed that the type 2 ruptures were likely iatrogenic and related to resection of the papillary muscles.

It was not long before surgeons realized that ventricular rupture may occur hours or days later or form a false aneurysm in the posterior wall of the ventricle that is recognized only years later. ${ }^{3-5}$ Miller and colleagues ${ }^{6}$ proposed that preservation of the posterior leaflet, or at least part of it, may prevent this dreadful complication of MVR. There was not a single case of ventricular rupture in a series of 513 patients who had MVR with preservation of the posterior leaflet reported by Deniz and colleagues. ${ }^{7}$ In their series of 2560 patients with MVR, there were 23 cases of ventricular rupture, none among the 513 who had preservation of the posterior leaflet and 7 among the 372 who underwent reoperation. ${ }^{7}$

The hypothesis that type 2 rupture is related to trauma to the papillary muscles during MVR due to excessive traction during resection of the mitral valve or direct severance of the endocardium in the areas of the papillary muscles is probably correct in our view. ${ }^{2}$ The physiopathology of type 1 rupture is more complicated and not completely

From the Division of Cardiac Surgery of the Peter Munk Cardiac Centre at Toronto General Hospital and the University of Toronto, Toronto, Ontario, Canada.

Received for publication Feb 12, 2020; revisions received Feb 12, 2020; accepted for publication May 15, 2020; available ahead of print June 18, 2020.

Address for reprints: Tirone E. David, MD, 200 Elizabeth St, 4N453, Toronto, Ontario, Canada M5G 2C4 (E-mail: tirone.david@uhn.ca).

JTCVS Open 2020;3:48-9

2666-2736

Copyright $(2020$ The Authors. Published by Elsevier Inc. on behalf of The American Association for Thoracic Surgery. This is an open access article under the CC BY-NCND license (http://creativecommons.org/licenses/by-nc-nd/4.0/).

https://doi.org/10.1016/j.xjon.2020.05.004

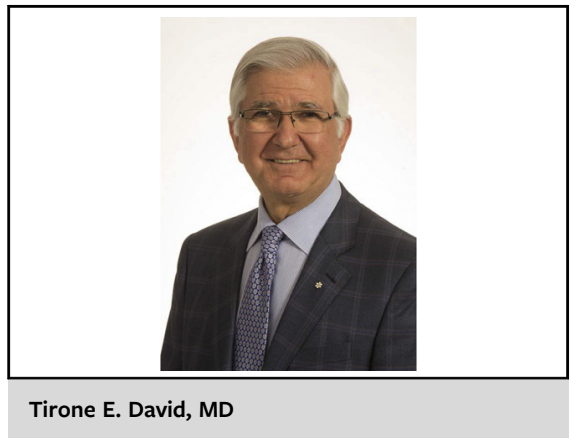

CENTRAL MESSAGE

Rupture of the left ventricle

following mitral valve replacement is best managed by explanting the prosthetic valve and covering the ruptured area with a pericardial patch.

See Commentary on page 50.

understood. The fibrous skeleton of the heart is an incomplete structure along the posterior mitral annulus, and the posterior leaflet of the mitral valve is often attached directly to the ventricular wall without a clear fibrous annulus. ${ }^{8}$ That is likely why patients with advanced myxomatous disease of the mitral valve may develop so-called "mitral annulus dysjunction." With such a flimsy attachment to the ventricular muscle, it is not surprising that blood may find its way in between the suture line that secures the prosthetic mitral valve and the ventricular muscle. Factors associated with ventricular rupture include older age, rheumatic mitral stenosis, and dystrophic calcification of the mitral annulus. ${ }^{3,6,7}$ Rupture can occur after isolated MVR or in concert with other valves. ${ }^{3}$

Most ruptures appear to occur while the patient is still the operating room. ${ }^{3,7}$ When this happens, most surgeons attempt repair by applying large sutures buttressed on Teflon felt or by suturing or gluing a patch in the ruptured area, but the operative mortality is high. Our experience is limited to 11 patients: 7 in whom rupture occurred in the operating room, all of whom were saved; 3 patients in whom it occurred in the intensive care unit from 3 to 11 hours after discontinuation of cardiopulmonary bypass, all who 
exsanguinated before they could be placed back on cardiopulmonary bypass; and 1 who died at home 9 days after surgery, in whom autopsy showed a type 1 ventricular rupture after a redo MVR and tricuspid annuloplasty.

We believe that the best approach to treating this horrific complication of MVR is to place the patient back on cardiopulmonary bypass and under cold blood cardioplegic arrest, explant the mitral valve prosthesis, and patch the posterior atrioventricular groove with fresh autologous pericardium or glutaraldehyde fixed bovine pericardium. Our experience with patching the ventricular endocardium has taught us that the patch should always be larger than the area in which it is sewn. We first reported on this technique in 1987, and since then have had another 5 successful cases of rupture occurring in the operating room. ${ }^{10}$ We lost 4 patients who experienced rupture in the intensive care unit or at home soon after discharge.

Hematoma in the atrioventricular groove is not rare after MVR, and it is difficult to know what to do. I tend to keep the patient in the operating room for an extra 30 minutes to 1 hour, and if the hematoma does not increase in size, I leave it alone and follow with computed tomography scan of the heart before the patient is discharged from the hospital. I do not recall ever having a patient who experienced rupture during follow-up. There are case reports of patients in whom a false aneurysm formed but resolved spontaneously over time and of patients who progressed to a false aneurysm that required reoperation. ${ }^{11,12}$

\section{Conflict of Interest Statement}

The author reported no conflicts of interest.
The Journal policy requires editors and reviewers to disclose conflicts of interest and to decline handling or reviewing manuscripts for which they may have a conflict of interest. The editors and reviewers of this article have no conflicts of interest.

\section{References}

1. Treasure RL, Rainer WG, Strevey TE, Sadler TR. Intraoperative left ventricular rupture associated with mitral valve replacement. Chest. 1974;66:511-4.

2. Zacharias A, Groves LK, Cheanvechai C, Loop FD, Effler DB. Rupture of the posterior wall of the left ventricle after mitral valve replacement. J Thorac Cardiovasc Surg. 1975;69:259-63.

3. Dark JH, Bain WH. Rupture of posterior wall of left ventricle after mitral valve replacement. Thorax. 1984;39:905-11.

4. Tarkka M, Pokela R, Kärkölä P. Delayed left ventricular rupture after mitral valve replacement. Eur J Cardiothorac Surg. 1987;1:104-9.

5. Lee JH, Jeon SC, Jang HJ, Chung WS, Kim YH, Kim H. Left ventricular pseudoaneurysm after valve replacement. Korean J Thorac Cardiovasc Surg. 2015; 48:63-6.

6. Miller DW Jr, Johnson DD, Ivey TD. Does preservation of the posterior chordae tendineae enhance survival during mitral valve replacement? Ann Thorac Surg. 1979;28:22-7.

7. Deniz H, Sokullu O, Sanioglu S, Sargin M, Ozay B, Ayoglu U, et al. Risk factors for posterior ventricular rupture after mitral valve replacement: results of 2560 patients. Eur J Cardiothorac Surg. 2008;34:780-4.

8. Angelini A, Ho SY, Anderson RH, Davies MJ, Becker AE. A histological study of the atrioventricular junction in hearts with normal and prolapsed leaflets of the mitral valve. Br Heart J. 1988;59:712-6.

9. Hutchins GM, Moore GW, Skoog DK. The association of floppy mitral valve with disjunction of the mitral annulus fibrosus. N Engl J Med. 1986;314 535-40.

10. David TE. Left ventricular rupture after mitral valve replacement: endocardial repair with pericardial patch. J Thorac Cardiovasc Surg. 1987;93: 935-6.

11. Nagamine H, Date Y, Takagi T, Kawase Y. To repair or not to repair: a case report of atrioventricular groove hematoma during mitral valve surgery. J Cardiothorac Surg. 2019;14:1-5.

12. Agudo-Quilez P, Pozo E, Benedicto A, Reyes G, Olivera MJ, Caballero P, et al. Atrioventricular septum pseudoaneurysm as late complication after repeated mitral valve replacement. Ann Thorac Surg. 2017;103:e55-6. 